\title{
Evaluating the Decision-to-Delivery Interval in Emergency Cesarean Sections and its Impact on Neonatal Outcome
}

\author{
JANNA-ALICA BRANDT, BERND MORGENSTERN, FABINSHY THANGARAJAH, BERTHOLD GRÜTTNER, \\ SEBASTIAN LUDWIG, CHRISTIAN EICHLER, JESSIKA RATIU, PETER MALLMANN and DOMINIK RATIU \\ Department of Obstetrics and Gynecology, Medical Faculty, University Hospital Cologne, Cologne, Germany
}

\begin{abstract}
Background/Aim: In Germany, performance of an emergency Cesarean section (ECS) is recommended within an interval of $\leq 20$ min from decision to delivery (DDI). The aim of the study was to assess the duration of DDI in ECS as well as its impact on neonatal outcome. Patients and Methods: Data from 437 patients at a single, tertiary care hospital were retrospectively analysed regarding influence on the duration of DDI. Subsequently the impact of DDI on neonatal outcome and incidence of adverse neonatal outcome was analysed. Results: DDI of ECS performed outside core working hours was significantly prolonged $(p<0.001)$. Shorter DDI showed a statistically worse arterial cord blood $p H(p=0.001, r=0.162)$ and base excess ( $p=0.05 ; r=0.094)$. Duration of DDI had no significant impact on the incidence of adverse neonatal outcome $(p=0.123)$. Conclusion: Awareness of influence on DDI might contribute to expediting DDI, but duration of DDI showed no impact on the incidence of adverse neonatal outcome. Data were not adequate to suggest a recommendation for DDI time standards.
\end{abstract}

Cesarean section is the most commonly performed major surgery in obstetrics. In an emergency its immediate performance seems to be necessary in order to minimize the risk of permanent fetal damages and to prevent fatal complications. Emergency Cesarean section (ECS) is required in approximately $1 \%$ of pregnancies (1).

In Germany the time interval from indicating an ECS until the actual delivery of the neonate, also known as decision to delivery interval (DDI), is recommended to be $\leq 20 \mathrm{~min}$ (2).

This article is freely accessible online.

Correspondence to: Janna-Alica Brandt, Department of Obstetrics and Gynecology, Medical Faculty, University Hospital Cologne, Kerpener Str. 34, 50931 Cologne, Germany, Tel: +49 02214784910 , Fax: +49 02214784929, email: janna-alica.brandt@uk-koeln.de

Key Words: Emergency Cesarean section, decision-to-delivery interval, neonatal outcome.
However the American College of Obstetricians and Gynaecologists and the Royal College of Obstetricians and Gynaecologists suggest a decision to incision interval (DTI) or DDI of $\leq 30 \mathrm{~min}(3,4)$. Scientific evidence to support these recommendations though is limited $(5,6)$. The aim of the study was to determine whether there were variables influencing the duration of DDI and if duration of DDI had an impact on neonatal outcome.

\section{Patients and Methods}

The present retrospective study was conducted at the University hospital Cologne, a single, tertiary care hospital in Germany. A total of 437 patients with a live singleton non-anomalous gestation who underwent ECS between January 2000 and January 2019 and complete dataset were included in the study. The dataset included the patients pre- and intraoperative status, as well as the postpartum neonate status. Based on the classification of urgency by the Royal College of Obstetricians and Gynaecologists Cesarean section was defined as ECS if there was an immediate threat to life of the patient or the fetus (3). Indications for ECS included fetal bradycardia or other severe abnormal findings in fetal cardiac rhythm, umbilical cord prolapse, placental abruption, placenta praevia and abundant bleeding, uterine rupture, amniotic infection syndrome, eclampsia, maternal cardiac arrest and other.

An adverse neonatal outcome was determined to be present if any of the following occurred: low 5-min APGAR-score ( $\leq 7)$ (7), low $\mathrm{pH}$ in arterial cord blood $(\leq 7.0)$ or low base excess in arterial cord blood $(\leq-16)$.

Since in the present study there were only few cases in which the DDI exceeded the recommended time interval we abstained from analysing influencing factors causing a transgression of DDI or comparing the neonatal outcome of those born within the targeted interval and those who were not. Instead, we examined the impact of different factors on the duration of DDI as well as the impact of duration of DDI on neonatal outcome independently from the recommended time interval.

Statistical analysis. Nominal data are presented as counts and percentages, ordinal data are presented as median and interquartile range (IQR) or range, whereas continuous data are presented as mean with standard deviation (SD). Kolmogorov-Smirnov test showed no standard distribution for the decision to delivery interval so non-parametric tests, i.e. Mann-Whitney or Kruskal-Wallis were 
Table I. Analysis of decision to delivery interval, preoperative variables.

\begin{tabular}{|c|c|c|c|c|c|}
\hline \multirow[t]{2}{*}{ Variables } & \multirow[t]{2}{*}{ Number (\%) } & \multicolumn{2}{|c|}{ Decision to delivery interval, min } & \multirow[t]{2}{*}{$p$-Value ${ }^{1}$} & \multirow[t]{2}{*}{$r$-Value ${ }^{2}$} \\
\hline & & Mean (SD) & Median (Range) & & \\
\hline Overall & $437(100)$ & $7.66(4.389)$ & $7(0-55)$ & & \\
\hline Maternal age & & & & 0.524 & \\
\hline$<35$ years & 258 (59) & $7.74(4,6)$ & $7.0(2-55)$ & & \\
\hline$\geq 35$ years & $179(41)$ & $7.54(4,074)$ & $7.0(0-35)$ & & \\
\hline $\begin{array}{l}\text { Gestational age } \\
\text { in completed weeks }\end{array}$ & & & & 0.093 & \\
\hline$\leq 34$ & $103(23.6)$ & $8.14(4.529)$ & $7.0(0-35)$ & & \\
\hline $35-37$ & $87(19.9)$ & $8.23(4.477)$ & $7.0(2-35)$ & & \\
\hline $38-40$ & $152(34.8)$ & $7.07(3.332)$ & $6.0(2-25)$ & & \\
\hline$\geq 41$ & $95(21.7)$ & $7.57(5.459)$ & $7.0(0-55)$ & & \\
\hline $\begin{array}{l}\text { Diabetes mellitus or } \\
\text { gestational diabetes }\end{array}$ & & & & 0.614 & \\
\hline No & $401(91.8)$ & $7.72(4.518)$ & $7.0(0-55)$ & & \\
\hline Yes & $36(8.2)$ & $7.03(2.501)$ & $7.0(3-15)$ & & \\
\hline Maternal obesity & & & & 0.065 & \\
\hline No & $388(88.8)$ & $7.64(4.567)$ & $7.0(0-55)$ & & \\
\hline Yes & $49(11.2)$ & $7.84(2.593)$ & $8.0(3-15)$ & & \\
\hline $\begin{array}{l}\text { Previous Caesarean section } \\
\text { and/or uterine surgery }\end{array}$ & & & 0.158 & & \\
\hline No & $371(84.9)$ & $7.48(3.8)$ & $7.0(0-35)$ & & \\
\hline Yes & $66(15.1)$ & $8.7(6.762)$ & $7.0(2-55)$ & & \\
\hline Day of week & & & & 0.534 & \\
\hline Weekday (Mon. - Fri.) & $331(75.7)$ & $7.58(4.34)$ & $7.0(0-55)$ & & \\
\hline Weekend-day (Sat. - Sun.) & $106(24.3)$ & $7.92(4.397)$ & $7.0(2-35)$ & & \\
\hline Time of day & & & & $<0.001$ & 0.33 \\
\hline Core working hours & $177(40.5)$ & $6.79(4.06)$ & $6.0(0-55)$ & & \\
\hline Outside core working hours & $260(59.5)$ & $9.37(4.515)$ & $8.0(2-35)$ & & \\
\hline
\end{tabular}

${ }^{1} p$-Value was calculated using Mann-Whitney or Kruskal-Wallis test. ${ }^{2}$ Pearson correlation coefficient. SD: Standard deviation.

used to compare data. Effect sizes were calculated for significant results using the Pearson correlation coefficient.

Subsequently the impact of DDI on the neonatal outcome was analyzed. First, the Spearman correlation test was used to analyze the influence of DDI on 5-min APGAR, pH in arterial cord blood and base excess in arterial cord blood individually. Results are presented as $p$-values and correlation coefficients.

An analysis examining the impact of DDI on the incidence of an adverse neonatal outcome was conducted using a multivariate logistic regression model. Multivariate logistic regression analysis also contained additional variables which were conceivable to have an impact on the neonatal outcome in order to evaluate possible confounders. Results are presented as odds ratio (OR) with confidence limits and $p$-values. Analyses were conducted using the Statistical Package for the Social Science (Version 25; SPSS Inc, Chicago, IL). $p$-Values $\leq 0.05$ were considered statistically significant. A correlation coefficient ( $r$-value) of $0.1 \leq r<0.3$ was defined as weak correlation, $0.3 \leq r<0.5$ as medium correlation and $r>0.5$ as strong correlation.

\section{Results}

Description of patient database. Preoperative characteristics are summarized in Table I. The overall mean DDI was 7.66 $\min (\mathrm{SD}=4.389)$. DDI of $\leq 20 \mathrm{~min}$ could be achieved in $98.9 \%$ of emergency Cesarean sections. A total of $179(41 \%)$ of patients were over 35 years old. Most patients (34.8\%) were pregnant in between the $38^{\text {th }}-40^{\text {th }}$ completed week of gestation. Nevertheless $190(43.5 \%)$ patients had a premature delivery before $37^{\text {th }}$ completed weeks of gestation. Regarding medical conditions, $36(8.2 \%)$ of patients had diabetes mellitus or gestational diabetes mellitus, 49 (11.2\%) suffered from obesity and $66(15.1 \%)$ had previous uterine surgery, usually Cesarean section. A total of 331 (75.7\%) ECS were performed on weekdays (Monday-Friday). Regarding the time of day, 177 (40.5\%) procedures occurred during core working hours which were between 8 a.m. and 4 p.m., while $260(59.5 \%)$ procedures were performed outside core working hours between 4 p.m. and 8 a.m.

Postoperative variables are displayed in Table II. Most neonates were males (248 (56.8\%). Overall an adverse neonatal outcome was reported for 150 (34.3\%) newborns. The mean arterial cord blood $\mathrm{pH}$ was $7.19(\mathrm{SD}=0.129)$, mean arterial cord blood base excess was -7.6 ( $\mathrm{SD}=5.504)$. Median 1-min APGAR score was $7(\mathrm{IQR}=4)$, median 5-min APGAR 
Table II. Analysis of decision to delivery interval, postpartum neonatal variables.

\begin{tabular}{|c|c|c|c|c|}
\hline \multirow[t]{2}{*}{ Variables } & \multirow[t]{2}{*}{ Number $(\%)$} & \multicolumn{2}{|c|}{ Decision to delivery interval, min } & \multirow[t]{2}{*}{$p$-Value ${ }^{1}$} \\
\hline & & Mean $\left(\mathrm{SD}^{2}\right)$ & Median (Range) & \\
\hline Overall & $437(100)$ & $7.66(4,389)$ & $7(0-55)$ & \\
\hline Gender of neonates & & & & 0.844 \\
\hline Female & $189(43.2)$ & $7.33(3.023)$ & $7.0(0-20)$ & \\
\hline Male & $248(56.8)$ & $7.92(5.186)$ & $7.0(2-55)$ & \\
\hline Birthweight of neonates & & & & 0.064 \\
\hline$\leq 1,000 \mathrm{~g}$ & $24(5.5)$ & $7.54(2.992)$ & $7.5(0-15)$ & \\
\hline $1,001-1,500 \mathrm{~g}$ & $36(8.3)$ & $9.75(6.073)$ & $9.0(4-35)$ & \\
\hline $1,501-3,000 \mathrm{~g}$ & $185(42.3)$ & $7.41(3.748)$ & $7.0(2-35)$ & \\
\hline$>3,000 \mathrm{~g}$ & $192(43.9)$ & $7.53(4.658)$ & $7.0(2-55)$ & \\
\hline $1-\min \mathrm{APGAR}^{3}$ & & & & 0.838 \\
\hline$\leq 7$ & $271(62)$ & $7.57(3.815)$ & $7.0(2-35)$ & \\
\hline$>7$ & $166(38)$ & $7.81(5.2)$ & $7.0(0-55)$ & \\
\hline 5-min $\mathrm{APGAR}^{3}$ & & & & 0.646 \\
\hline$\leq 7$ & $137(31.4)$ & $7.46(3.319)$ & $7.0(3-22)$ & \\
\hline$>7$ & $300(68.6)$ & $7.75(4.801)$ & $7.0(0-55)$ & \\
\hline $10-$ min APGAR $^{3}$ & & & & 0.243 \\
\hline$\leq 7$ & $45(10.3)$ & $8.22(3.902)$ & $8.0(3-22)$ & \\
\hline$>7$ & $392(89.7)$ & $7.6(4.441)$ & $7.0(0-55)$ & \\
\hline $\mathrm{pH}$ in arterial cord blood & & & & 0.408 \\
\hline$\leq 7.0$ & $33(7.6)$ & $7.12(3.049)$ & $6.0(4-17)$ & \\
\hline$>7.0$ & $404(92.4)$ & $7.71(4.480)$ & $7.0(0-55)$ & \\
\hline Base excess arterial cord blood & & & & 0.348 \\
\hline$\leq-16$ & $33(7.6)$ & $7.72(4.500)$ & $7.0(0-55)$ & \\
\hline$>-16$ & $404(92.4)$ & $6.91(2.614)$ & $6.0(4-17)$ & \\
\hline Admission at NICU & & & & 0.581 \\
\hline No & $216(49.4)$ & $7.48(4.352)$ & $7.0(2-55)$ & \\
\hline Yes & $221(50.6)$ & $7.84(4.427)$ & $7.0(0-25)$ & \\
\hline Adverse neonatal outcome & & & & 0.570 \\
\hline No & $287(65.7)$ & $7.8(4.895)$ & $7.0(0-55)$ & \\
\hline Yes & $150(34.3)$ & $7.4(3.204)$ & $7.0(3-22)$ & \\
\hline
\end{tabular}

${ }^{1} p$-Value was calculated using Mann-Whitney or Kruskal-Wallis test. ${ }^{2}$ Standard deviation. ${ }^{3}$ Score with the components respiration, heart rate, muscle tone, skin color and reflexes. NICU: Neonatal intensive care unit.

score was $8(\mathrm{IQR}=2)$ and median 10-min APGAR score was $9(\mathrm{IQR}=2)$. More than half of the neonates $(50.6 \%)$ were admitted to the neonatal intensive care unit postnatally.

Influence on duration of the decision to delivery interval. Statistically, there was no significant difference in duration of DDI regarding maternal age $(p=0.524)$, gestational age $(p=0.093)$, diabetes $(p=0.614)$, maternal obesity $(p=0.065)$, previous uterine surgery $(p=0.158)$ or day of week on which the delivery occurred $(p=0.534)$. A significant result was found for the time of day $(p<0.001)$, at which ECS was performed only. Median DDI of ESC performed outside core working hours was higher $(8.0$, range $=2-35 \mathrm{~min})$ than during core working hours $(6.0$, range $=0-55 \mathrm{~min})$ (Table I).

Impact of decision to delivery interval on neonatal outcome. Duration of DDI did not statistically differ regarding sex of newborn $(p=0.844)$, fetal birth weight $(p=0.064), \mathrm{pH}$ in arterial cord blood $(p=0.408)$, base excess in arterial cord blood $(p=0.348), 1-$ min APGAR $(p=0.838), 5-$ min APGAR $(p=0.646), 10-\min$ APGAR $(p=0.243)$ or admission to neonatal intensive care unit $(p=0.581)$ (Table II).

Correlation analysis of the influence of DDI on the arterial cord blood $\mathrm{pH}$, base excess and the 5-min APGAR showed a significant, positive correlation for arterial cord blood $\mathrm{pH}$ $(p=0.001 ; r=0.162)$ and arterial cord base excess $(p=0.05$; $r=0.094)$. This indicates shorter DDI leading to lower fetal $\mathrm{pH}$ and base excess in arterial cord blood. Though correlation coefficient in both cases only suggests a weak association. No correlation was found for the 5-min APGAR $(p=0.578)$ (Table III).

Results of multivariate regression analysis are summarized in Table IV. Overall there was no statistically significant influence on the incidence of adverse neonatal outcome for any of the following: decision to delivery interval $(p=0.123)$, birth weight of newborn $(p=0.707)$, male 
Table III. Correlation analysis: Influence of the decision to delivery interval on neonatal outcome.

\begin{tabular}{|c|c|c|}
\hline & $p$-Value ${ }^{1}$ & Correlation coefficient \\
\hline Arterial cord blood $\mathrm{pH}$ & 0.001 & 0.162 \\
\hline Arterial cord blood base excess & 0.05 & 0.094 \\
\hline 5-minutes $\mathrm{APGAR}^{2}$ score & 0.578 & 0.027 \\
\hline
\end{tabular}

${ }^{1} p$-Value was calculated using Spearman correlation test. ${ }^{2}$ Score with the components respiration, heart rate, muscle tone, skin color and reflexes.

sex of newborn $(p=0.562)$ or pre-existing diabetes mellitus or gestational diabetes $(p=0.567)$. Despite DDI missing significance, OR (0.957) still suggested that shorter DDI increases the incidence of adverse neonatal outcome up to $0.5 \%$, showing a similar result as correlation between DDI and arterial cord blood $\mathrm{pH}$ and base excess. Increasing gestational age at the time of delivery was the only variable showing a significant impact ( $p=0.008)$. It was identified to have a protective effect, reducing the risk of an incidence of adverse neonatal outcome up to $13 \%(\mathrm{OR}=0.869)$.

\section{Discussion}

In this present study, delivery within $20 \mathrm{~min}$ after the decision for ECS was achieved in the great majority (98. $9 \%)$ of cases. With a mean DDI of $7.66 \mathrm{~min}(\mathrm{SD}=4.389)$ it was also performed perspicuously faster than recommended. When comparing these results with data on DDI from Germany corresponding results are found (8). In contrast several international studies did not accomplish incision or delivery for ECS, depending on whether the study had DTI or DDI as indicator, within the recommended time interval in a considerable proportion of patients (9-12). A possibly limited comparability due to these international differences must not be disregarded when discussing present results. Also varying definitions of the targeted time interval, indications for emergency caesarean section and neonatal outcome must be considered.

Influences on duration of decision to delivery interval. Overall, we identified ESC outside core working hours being accountable for prolongation of DDI. Other factors (e.g. maternal obesity, previous uterine surgery, day of week on which the ECS occurred) did not show any significant impact on duration of DDI respectively. When comparing the present results with those published in other studies conflicting statements are found.

Concerning time of day, at which the procedure occurred, analysis showed that DDI outside core working hours was significantly prolonged in comparison to DDI within core working hours. This finding is in agreement with Dunn et al.,
Table IV. Multivariate logistic regression analysis: impact on adverse neonatal outcome.

\begin{tabular}{|c|c|c|c|c|}
\hline & $p$-Value $^{1}$ & OR & 95\% Confidence & Interval \\
\hline $\begin{array}{l}\text { Decision to delivery } \\
\text { interval }\end{array}$ & 0.123 & 0.957 & 0.906 & 1.012 \\
\hline Birthweight & 0.707 & 1.000 & 1.0 & 1.001 \\
\hline Male sex of newborn & 0.562 & 1.132 & 0.744 & 1.722 \\
\hline $\begin{array}{l}\text { Diabetes mellitus or } \\
\text { gestational diabetes }\end{array}$ & 0.567 & 0.791 & 0.354 & 1.766 \\
\hline Gestational age $^{2}$ & 0.008 & 0.869 & 0.783 & 0.964 \\
\hline
\end{tabular}

${ }^{1} p$-Value was calculated using multivariate logistic regression. ${ }^{2}$ Completed weeks of gestation at time of delivery. OR: Odds ratio.

who on comparable clinical conditions also found a significant association between ECS performed outside office hours and prolonged DDI (13). A possible explanation might be that the healthcare team necessary to perform an ECS is not constantly present in the labour ward outside core working hours but, though still in-house, is on-call. Waiting for members of the healthcare team (theatre staff, obstetrician, paediatrician, anaesthetist) was also described as a perceived reason for delay in urgent ECS in tertiary care hospitals by Spencer and MacLennan (14). Though they did not investigate a delay regarding time of day, their results might still support out hypothesis. Contradicting results however were published by other studies (15-17). MacKenzie and Cooke for example could not demonstrate any influence of the time of day on DDI but, described a quicker delivery between 2 a.m. and 7 a.m. (16). They hypothesized that the absence of planned Cesarean sections and labour inductions might be the cause. Similar results were reported by Lim et $a l$, who also stated no significant difference in duration of DDI in crash Cesarean sections regarding office hours but reported a slightly shorter DDI after office hours (17).

Regarding the day of the week though no significant difference in duration of DDI was found. These findings agree with prior published reports $(10,16)$.

Even though the influence of maternal obesity on the duration of DDI in our study only showed a result on the threshold of significance other studies e.g. Conner et al. (18) reported that obesity in patients undergoing Cesarean section significantly prolonged the time interval from incision to delivery. This is consistent with the results of Turner and Warshak (19) who stated that DDI of $\leq 30$ min could not be achieved in a significant number of obese and morbidly obese patients undergoing ECS (defined as terminal bradycardia or cord prolapse). Reasons stated were problems with transport as well as a prolongation of the operative procedure itself. Due to operative reasons we also anticipated a prolongation of DDI in patients which had previous uterine surgery but failed to show a significant difference. Results of other 
studies however supported our hypothesis. Greenberg at al. (20) for instance investigated the incision to delivery interval in first repeat Cesarean sections and found that it was significantly increased in women with dense adhesions.

Other publications also analysed further variables including mode of anaesthesia $(16,21,22)$ and found a significant influence on DTI or DDI respectively with general anaesthesia being associated with shorter intervals than epidural or spinal anaesthesia. The mode of anaesthesia was not examined in the present study since all included patients received general anaesthesia.

Impact of decision to delivery interval on neonatal outcome. Though there was no significant difference in duration of DDI regarding neonatal outcome variables, we were able to show that shortened DDI resulted in a significantly worsened neonatal $\mathrm{pH}$ and base excess in arterial cord blood. At prima facie this may appear contradicting, but the inversed correlation might be explained when considering that an emergency Cesarean is performed more rapidly the greater the anticipated risk for the fetus or mother. Thereby resulting in shortened DDI being associated with worsened neonatal outcome. Comparable results were already described in prior studies $(16,23,24)$.

Even though we anticipated that a prolonged DDI would lead to an increased incidence of adverse neonatal outcome, we were unable to show any significant impact. Results were compliant with most published studies covering the topic (9, $11,12,21,23,25,26)$. For instance similar results were reported by Grobman et al. (23). They stated that even a decision to incision time $\geq 30 \mathrm{~min}$ in patients undergoing ECS for fetal indications was not associated with worsened neonatal outcome whereby it also needs to be considered that the most emergent indications for ECS, abruption and cord prolapse were excluded in the study. Likewise Tolcher et al. (11) who examined the impact of delivery interval on the neonatal outcome in ECS classified as category 1 by Lucas et al. (27) stated that "the neonatal outcome did not differ by delivery interval".

However in 2017 Heller et al. (28) reached another conclusion. They described a DDI of $\leq 20 \mathrm{~min}$ being associated with a significant improvement of neonatal outcome in ESC. for suspected or confirmed fetal asphyxia. Still, as already mentioned by the authors themselves it must be considered that because of the few cases used as reference criterion (536 cases $>20 \mathrm{~min}$ out of 39,291 neonates included), the statistical power might only be limited.

We identified gestational age to have a protective effect on the occurrence of adverse neonatal outcome. Similar results were reported by Berlit et al. (26). When evaluating these results though, morbidities of prematurity leading to erroneously low APGAR scores must be considered to be a possible confounder (29). As described by Catlin et al., preterm neonates with a normal fetal status, defined as normal arterial cord blood $\mathrm{pH}$ and base excess, may often receive a low APGAR score though it might reflect physiological developmental immaturity than fetal distress (30).

Discussing expedition of DDI, possible maternal complications must not be disregarded. Our data did not qualify to make a statement concerning maternal complications but Moroz et al. (31), for instance, reported that among women who underwent emergent repeat Cesarean section the risk of maternal complications was increased if the incision to delivery interval was $\leq 2 \mathrm{~min}$. Other studies, however, showed no impact of duration of DDI on maternal outcome $(9,23)$.

Our study demonstrated that time of day significantly influenced the duration of DDI. Acknowledging the present findings might contribute to expediting DDI and therefore achieve delivery or incision in the targeted interval. Still duration of DDI showed no significant impact on the incidence of adverse neonatal outcome. Present data were not adequate to suggest a recommendation for DDI time standards. Further research in order to examine suitable DDI time standards is needed.

Strengths and limitations. The present study includes a comparatively high number of patients, considering low frequency of ECS. It was conducted at a tertiary care hospital in Germany in which there is a universal policy and great experience of collecting data on DDI as well as drawing umbilical cord blood and determining APGAR scores ensuring data quality and decreasing bias. Generalizability to other healthcare facilities though might be limited. We excluded multiple and anomalous gestations which lead to a more homogenous study population and a consequently improved comparability though occurrence of emergency caesarean section might be underestimated. Despite its retrospective and single-center nature our study contributes to the still relatively few information available on ECS. Alternative conclusions may be found with larger propensity-matched or randomized, prospective studies.

\section{Conflicts of Interest}

The Authors have nothing to disclose.

\section{Author's Contributions}

JAB was involved with project development, data collection, statistical analysis and manuscript writing, DR with project development, data collection and manuscript editing, FT, BG, SL, $\mathrm{CE}, \mathrm{JR}, \mathrm{BM}$ and PM with manuscript editing.

\section{Acknowledgements}

The Authors would like to thank Elena Gilman for reviewing the statistical analysis. 


\section{References}

1 Lagrew DC, Bush MC, McKeown AM and Lagrew NG: Emergent (crash) cesarean delivery: indications and outcomes. Am J Obstet Gynecol 194(6): 1638-1643, 2006. PMID: 16731082. DOI: 10.1016/j.ajog.2006.03.007

2 Bundesgeschäftsstelle-Qualitätssicherung gGmbH: Geburtshilfe. In: Qualität sichtbar machen: BQS-Qualitätsreport 2005. Mohr VD, Bauer J, Döbler K, Eckert O, Fischer B, Woldenga C, Höfele F $1^{\text {st }}$ ed. Düsseldorf, BQS Bundesgeschäftsstelle Qualitätssicherung, pp 40, 2005.

3 National Collaborating Centre for Women's and Children's Health Commissioned by the National Institute for Health and Clinical Excellence: Caesarean section. London, Royal College of Obstetricians and Gynaecologists press, pp 117-162, 2011.

4 American College of Obstetricians and Gynecologists: Committee on Professional Standards: Standards for obstetricgynecologic services $7^{\text {th }}$ ed. Washington, DC, American College of Obstetricians and Gynecologists, pp 39, 1989.

5 American Academy of Pediatrics, American College of Obstetricians and Gynecologists: Guidelines for perinatal care $8^{\text {th }}$ ed. Elk Grove Village, IL , Washington, DC, American Academy of Pediatrics; American College of Obstetricians and Gynecologists, pp 267, 2017.

6 Arbeitsgemeinschaft der Wissenschaftlichen Medizinischen Fachgesellschaften (AWMF): S3-Leitlinie 015-084: Die Sectio caesarea. AWMF, 2020. Available at: https://www.awmf.org/ leitlinien/detail/11/015-084.html [Last accessed on 08 July 2020]

7 Apgar V: A proposal for a new method of evaluation of the newborn infant. Curr Res Anesth Analg 32(4): 260-267, 1953. PMID: 13083014.

8 Institut für Qualitätssicherung und Transparenz im Gesundheitswesen (IQTIG): 1058 E-E-Zeit bei Notfallkaiserschnitt über 20 Minuten. In: Bundesauswertung zum Erfassungsjahr 2016, Geburtshilfe, Qualitätsindikatoren. Berlin, IQTIG, pp 17-19, 2017.

9 Bloom SL, Leveno KJ, Spong CY, Gilbert S, Hauth JC, Landon MB, Varner MW, Moawad AH, Caritis SN, Harper M, Wapner RJ, Sorokin Y, Miodovnik M, O'sullivan MJ, Sibai BM, Langer $\mathrm{O}$ and Gabbe SG: Decision-to-incision times and maternal and infant outcomes. Obstet Gynecol 108(1): 6-11, 2006. PMID: 16816049. DOI: 10.1097/01.AOG.0000224693.07785.14

10 Chauleur C, Collet F, Furtos C, Nourrissat A, Seffert P and Chauvin F: Identification of factors influencing the decision-todelivery interval in emergency caesarean sections. Gynecol Obstet Invest 68(4): 248-254, 2009. PMID: 19776612. DOI: $10.1159 / 000239783$

11 Tolcher M, Johnson R, El-Nashar S and West C: Decision-toincision time and neonatal outcomes: A systematic review and meta-analysis. Obstet Gynecol 123(3): 536-548, 2014. PMID: 24499762. DOI: 10.1097/AOG.0000000000000132

12 Mishra N, Gupta R and Singh N: Decision delivery interval in emergency and urgent caesarean sections: Need to reconsider the recommendations? J Obstet Gynecol India 68(1): 20-26, 2018. PMID: 29391671. DOI: 10.1007/s13224-017-0991-6

13 Dunn CN, Zhang Q, Sia JT, Assam PN, Tagore S and Sng BL: Evaluation of timings and outcomes in category-one caesarean sections: A retrospective cohort study. Indian J Anaesth $60(8)$ : 546-551, 2016. PMID: 27601736. DOI: 10.4103/00195049.187782
14 Spencer MK, and MacLennan AH: How long does it take to deliver a baby by emergency caesarean section? Aust N Z J Obstet Gynaecol 41(1): 7-11, 2001. PMID: 11284651. DOI: 10.1111/j.1479-828x.2001.tb01287.x

15 Hein A, Thalen D, Eriksson Y and Jakobsson JG: The decision to delivery interval in emergency caesarean sections: Impact of anaesthetic technique and work shift. F1000Res 6: 1977, 2017. PMID: 29225780. DOI: 10.12688/f1000research.13058.2

16 MacKenzie IZ and Cooke I: What is a reasonable time from decision-to-delivery by caesarean section? Evidence from 415 deliveries. Br J Obstet Gynaecol 109(5): 498-504, 2002. PMID: 12066937. DOI: 10.1111/j.1471-0528.2002.01323.x

17 Lim Y, Shah M, and Tan H: Evaluation of surgical and anaesthesia response times for crash caesarean sections - An audit of a singapore hospital. Ann Acad Med Singapore 34(10): 606-610, 2005. PMID: 16382245.

18 Conner SN, Tuuli MG, Longman RE, Odibo AO, Macones GA and Cahill AG: Impact of obesity on incision-to-delivery interval and neonatal outcomes at cesarean delivery. Am J Obstet Gynecol 209(4): 386.e1-386.e6, 2013. PMID: 23727523. DOI: 10.1016/j.ajog.2013.05.054

19 Turner E and Warshak CR: Cesarean for non-reassuring fetal status: effect of obesity on decision to delivery interval. J Perinatol 39(6): 814-819, 2019. PMID: 30858611. DOI: 10.1038/s41372-019-0351-8

20 Greenberg MB, Daniels K, Blumenfeld YJ, Caughey AB and Lyell DJ: Do adhesions at repeat cesarean delay delivery of the newborn?. Am J Obstet Gynecol 205(4): 380.e1-385, 2011. PMID: 21864825. DOI: 10.1016/j.ajog.2011.06.088

21 Pearson GA and MacKenzie IZ: Factors that influence the incision-delivery interval at caesarean section and the impact on the neonate: a prospective cohort study. Eur J Obstet Gynecol Reprod Biol 169(2): 197-201, 2013. PMID: 23597556. DOI: 10.1016/j.ejogrb.2013.02.021

22 Dunphy BC, Robinson JN, Shell OM, Nicholls JSD and Gillmer MDG: Caesarean section for fetal distress, the interval from decision to delivery, and the relative risk of poor neonatal condition. J Obstet Gynaecol 11(4): 241-244, 1991. DOI: $10.3109 / 01443619109027807$

23 Grobman WA, Bailit J, Sandoval G, Reddy UM, Wapner RJ, Varner MW, Thorp JM, Caritis SN, Prasad M, Tita ATN, Saade GR, Sorokin Y, Rouse DJ, Blackwell SC and Tolosa JE: The association of decision-to-incision time for cesarean delivery with maternal and neonatal outcomes. Am J Perinatol 35(3): 247-253, 2018. PMID: 28915515. DOI: 10.1055/s-0037-1606641

24 Hillemanns P, Strauss A, Hasbargen U, Schulze A, GenzelBoroviczeny O, Weninger E and Hepp H: Crash emergency cesarean section: decision-to-delivery interval under $30 \mathrm{~min}$ and its effect on Apgar and umbilical artery $\mathrm{pH}$. Arch Gynecol Obstet 273(3): 161-165, 2005. PMID: 16044190. DOI: 10.1007/s00404-005-0045-7

25 Nasrallah FK, Harirah HM, Vadhera R, Jain V, Franklin LT and Hankins GDV: The 30-minute decision-to-incision interval for emergency cesarean delivery: fact or fiction? Am J Perinatol 21(2): 63-68, 2004. PMID: 15017468. DOI: 10.1055/s-2004820513

26 Berlit S, Welzel G, Tuschy B, Nickol J, Hornemann A, Sütterlin $\mathrm{M}$ and Kehl S: Emergency caesarean section: risk factors for adverse neonatal outcome. Arch Gynecol Obstet 287(5): 901905, 2013. PMID: 23241729. DOI: 10.1007/s00404-012-2679-6 
27 Lucas DN, Yentis SM, Kinsella SM, Holdcroft A, May AE, Wee $\mathrm{M}$ and Robinson PN: Urgency of caesarean section: A new classification. J R Soc Med 93(7): 346-350, 2000. PMID: 10928020. DOI: 10.1177/014107680009300703

28 Heller G, Bauer E, Schill S, Thomas T, Louwen F, Wolff F, Misselwitz B, Schmidt S and Veit C: Decision-to-delivery time and perinatal complications in emergency cesarean section. Dtsch Arztebl Int 114(35-36): 589-596, 2017. PMID: 28927497. DOI: 10.3238/arztebl.2017.0589

29 Laptook AR: Birth asphyxia and hypoxic-ischemic brain injury in the preterm Infant. Clin Perinatol 43(3): 529-545, 2016 PMID: 27524452. DOI: 10.1016/j.clp.2016.04.010

30 Catlin EA, Carpenter MW, Brann BS, Mayfield SR, Shaul PW, Goldstein $\mathrm{M}$ and $\mathrm{Oh} \mathrm{W}$ : The Apgar score revisited: Influence of gestational age. J Pediatr 109(5): 865-868, 1986. PMID: 3772665. DOI: $10.1016 / \mathrm{s} 0022-3476(86) 80715-6$

31 Moroz L, DiNapoli M, D'Alton M and Gyamfi-Bannerman C: Surgical speed and risk for maternal operative morbidity in emergent repeat cesarean delivery. Am J Obstet Gynecol 213(4): 584.e1-584.e6, 2015. PMID: 26144412. DOI: 10.1016/j.ajog. 2015.06 .055

Received July 11, 2020

Revised July 28, 2020

Accepted July 31, 2020 